\title{
THE TEMPERATURE DEPENDENCE \\ OF AN EQUILIBRIUM THERMOEMITTING \\ CHARGE OF A METALLIC PARTICLE SURROUNDED WITH A NANODISPERSE CONDENSED PHASE
}

\author{
L.A. LYALIN, K.I. SEMENOV, A.K. SEMENOV, V.V. KALINCHAK, \\ N.KH. KOPYT
}

PACS 82.70.-y, 44.35.+c (C) 2011
I.I. Mechnikov Odessa National University

(2, Dvoryanskaya Str., Odessa, Ukraine; e-mail: semenovki@te.net.ua)

\begin{abstract}
The photos, which are done by an electron microscope, of the condensed disperse phase surrounding a high-temperature metal particle are presented. The dependence of the concentration of the condensed dispersive phase (CDP) which surrounds a hightemperature metal particle upon the temperature of the particle is obtained. The dependence of the concentration of electrons in CDP on the temperature of a particle is obtained. The condition of charge equilibrium of a metal particle with CDP surrounding it is obtained. The dependence of the equilibrium charge of a metal particle surrounded with CDP on the temperature of a particle in the positive and negative regions is obtained. The obtained results may be used in researches of the processes of burning of metallized fuels and in studies of dust plasma.
\end{abstract}

The researches of electrophysical processes in disperse systems at high temperatures are carrying out intensively [1-8]. In spite of this, there is no sufficiently full idea of the processes of charge transfer in such systems. While researching the process of thermoemission charging of high-temperature metallic particles surrounded with CDP, it was assumed that the volume charge of electrons in CDP corresponds to a saturated electron gas. In this case, the concentration of electrons does not depend upon the concentration of CDP, but it is determined by the temperature only [1-4]. This hypothesis comes true under the condition $k T /\left(e^{2} / 4 \pi \varepsilon_{0} r_{\mathrm{CDP}}\right)>1 / 2 \pi[9]$. Here, $k$ is the Boltzmann constant, $T$ is the temperature, $e$ is the electron charge, $\varepsilon_{0}$ is the electric constant. Such a situation is possible if the characteristic dimensions of CDP particles are of the order of $10^{3} \AA$. The research of CDP with the help of an electron microscope is a complicated problem. Therefore, the given work examined another critical case of nano-disperse CDP where the size of its particles is of the order of $10 \AA$. In this case, the concentration of electrons depends on the concentration of CDP. The process of thermoemission charging of a spherical metallic particle is determined by a high temperature of the particle $T_{1}$. Under such a condition at some distance from the particle surface, CDP is formed and it consists of condensation products of the particle material (see Fig. 1).

CDP can appear on molecules of metal oxide in the process of metal evaporation. In particular, it was found that CDP is formed while evaporating copper, tantalum, molybdenum, and tungsten particles $[1,2,4]$. Some thermal and electrophysical characteristics of the metal of a particle and CDP which surrounds it are presented in Table.

We denote the maximum temperature of the stable state of metal oxides by $T_{2}$. Oxide disintegrates at temperatures $T>T_{2}$. CDP is formed at some distance from the evaporating particle if the particle temperature is $T_{1}>T_{2}$. Let's take the next scheme of CDP formation in the space surrounding the particle. Vapors of metal which appear at the particle surface as a result of the diffusion are moving to the cold region. CDP is formed at a temperature $T \leq T_{2}$ as a result of the condensation of metal vapors and the interaction of metal

Some thermal electrophysical characteristics of the metal of a particle and CDP surrounding it

\begin{tabular}{|c|c|c|c|c|c|c|c|}
\hline & $\begin{array}{c}T_{2}, \\
\mathrm{~K}\end{array}$ & $\begin{array}{c}T_{\text {melt }}, \\
\mathrm{K}\end{array}$ & $\begin{array}{c}T_{\text {boil }}, \\
\mathrm{K}\end{array}$ & $\begin{array}{c}\Delta L, \\
\mathrm{~kJ} / \mathrm{mol}\end{array}$ & $\begin{array}{c}L, \\
\mathrm{~kJ} / \mathrm{mol}\end{array}$ & $\begin{array}{c}A_{1}, A_{2} \\
\mathrm{eV}\end{array}$ & $\begin{array}{c}r_{w}, \\
\AA\end{array}$ \\
\hline $\mathrm{Cu}$ & & 1356 & 2873 & 13 & 305 & $\begin{array}{c}\text { melt } \\
5.5 \\
\text { solid } \\
4.4\end{array}$ & \\
\hline Mo & & 2893 & 5073 & 27.9 & 506 & 4.3 & \\
\hline $\mathrm{Ta}$ & & 3269 & 5573 & 24.7 & 754 & 4.12 & \\
\hline W & & 3683 & 6203 & 35 & 736 & 4.54 & \\
\hline $\mathrm{Cu}_{2} \mathrm{O}$ & 2073 & & & & & 5.16 & 2.12 \\
\hline $\mathrm{MoO}_{3}$ & 1428 & & & & & 4.48 & 2.3 \\
\hline $\mathrm{Ta}_{2} \mathrm{O}_{5}$ & 1743 & & & & & 4.85 & 2.72 \\
\hline $\mathrm{WO}_{2}$ & 2000 & & & & & 5.24 & 1.92 \\
\hline
\end{tabular}




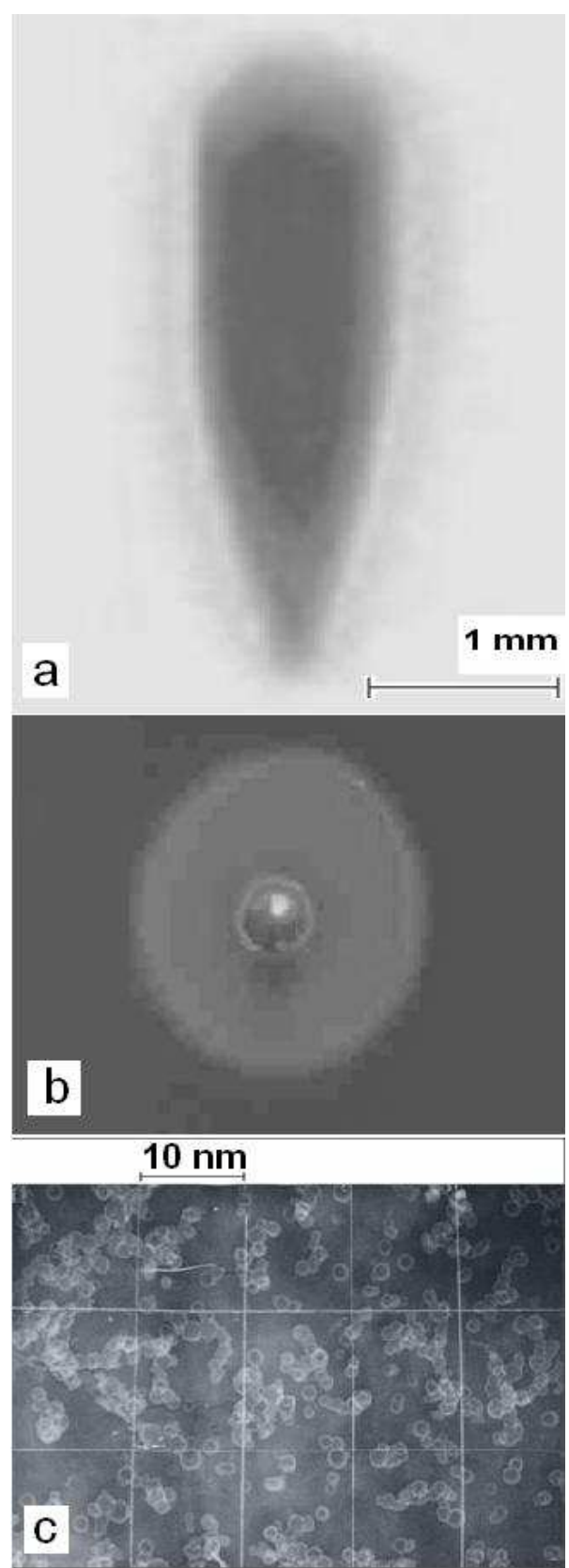

Fig. 1. The appearance of the condensed disperse phase by the movement of a particle - $a$; by the precipitation on the substrate $-b$; on the photo from an electron microscope $-c$

atoms with oxygen. Let's suppose that the most part of metal atoms is connected in particles of CDP so that the density of free metal atoms is negligible [10]. This condition corresponds to the intense process of condensation in CDP. Let's considered that CDP particles of a middle size contain approximately $N=1000$ molecules of a

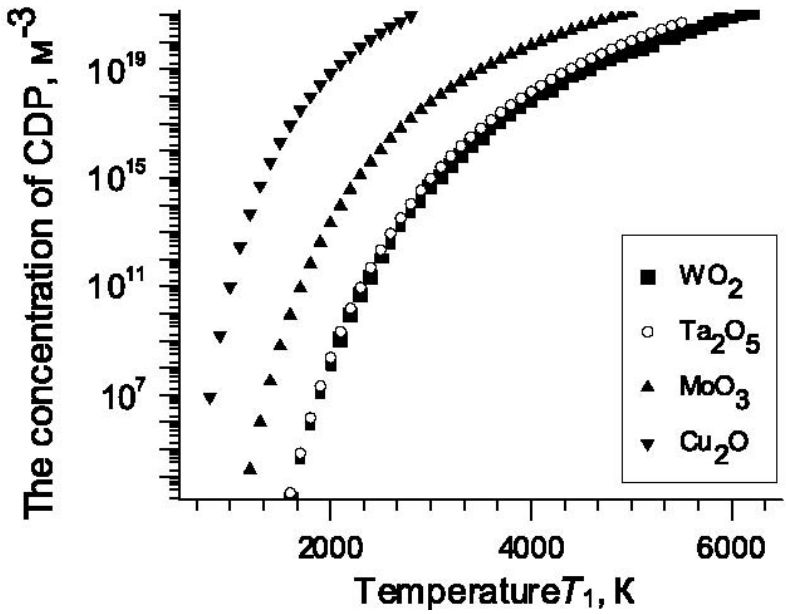

Fig. 2. Dependence of the concentration of CDP particles on the temperature of a particle

metal oxide [10]. The characteristic size of particles is determined by a sphere radius which depends on the mass of this particle $r_{\mathrm{CDP}}=r_{\mathrm{W}} N^{1 / 3}$. Here $r_{\mathrm{W}}=(3 \mu / 4 \pi \rho)^{1 / 3}$ is the Wigner-Seitz radius, $\mu$ is the mass of an oxide molecule, and $\rho$ is the macroscopic oxide density. The estimations show that the characteristic particle size of oxide is equal to $19-27 \AA$. These data are in the satisfactory conformity with experimentally defined sizes of CDP particles [11]. The dependence of the concentration of CDP particles near the particle surface upon its temperature $T_{1}$ in the interval $T_{\text {boil }} \geq T_{1} \geq T_{\text {melt }}$ will be found with the use of the Clausius-Clapeyron equation

$n_{\mathrm{CDP}}=\frac{P_{\mathrm{atm}}}{k Z N T_{1}} \exp \left\{\frac{L}{R}\left(\frac{1}{T_{\text {boil }}}-\frac{1}{T_{1}}\right)\right\}$.

At the temperature of the particle $T_{\text {melt }}>T_{1}$, the analogous dependence has the form

$n_{\mathrm{CDP}}=\frac{P_{\text {melt }}}{k Z N T_{1}} \exp \left\{\frac{L+\Delta L}{R}\left(\frac{1}{T_{\text {melt }}}-\frac{1}{T_{1}}\right)\right\}$.

In this case, $T_{\text {melt }}$ and $T_{\text {boil }}$ are the temperatures of melting and boiling of a metal, respectively, $P_{\text {atm }}$ and $P_{\text {melt }}$ are, respectively, the normal atmospheric pressure and the pressure of saturation vapors of metals at the temperature of melting, $L$ and $\Delta L$ are, respectively, the molar heat of evaporation at the temperature of boiling and the molar heat of metal melting, $R$ is the universal gas constant, and $Z$ is the number of metal atoms in one molecule of a metal oxide. The calculated dependence of the concentration of CDP which surrounds the particle on its temperature $T_{1}$ is presented in Fig. 2. 


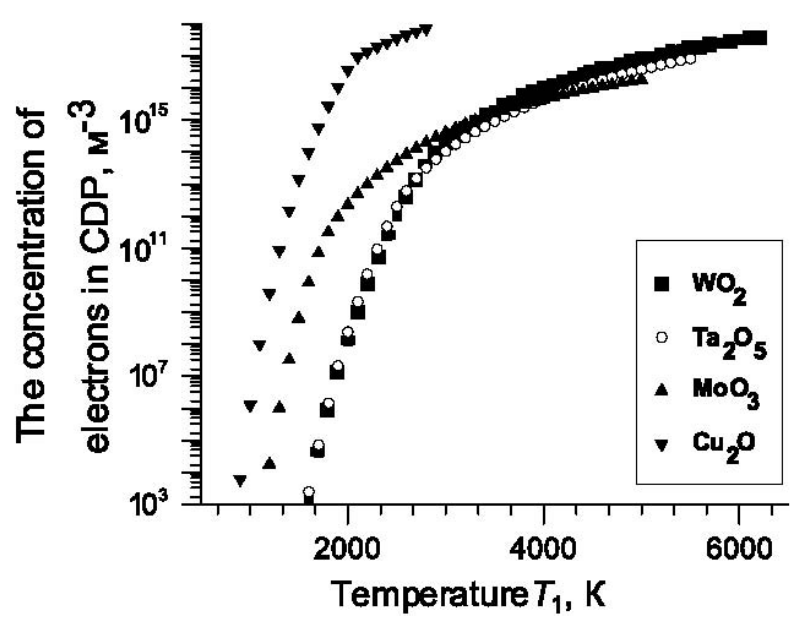

Fig. 3. Dependence of concentration of electrons in CDP on the temperature of a particle $T_{1}$

The correlation between the concentration of charged and neutral particles in CDP is defined by the Saha equation

$\frac{n_{e} n_{i}}{n_{n}}=2\left(\frac{2 \pi m_{e} k T}{h^{2}}\right)^{3 / 2} \exp \left(-\frac{A_{2}}{k T}\right)$.

Here, $n_{e}, n_{i}$, and $n_{n}$ are the concentrations of electrons and positively charged and neutral CDP particles, respectively, $m_{e}$ is the electron mass, $h$ is the Planck constant, and $A_{2}$ is the work function of an electron from a CDP particle. It was shown that the work function of an electron from the surface of a small particle (cluster) is more than the work function of an electron from the flat surface of a substance by the value $\Delta A_{2}=(3 / 8)\left(e^{2} / 4 \pi \varepsilon_{0} r_{\mathrm{CDP}}\right)$ [12]. In our situation, $A_{2}=A_{\infty}+Q^{1 / 2} e^{3 / 2} 4 \pi \varepsilon_{0} r_{\mathrm{CDP}}$, where $A_{\infty}$ is the work function of an electron from the flat surface. Taking into consideration that $n_{e}=n_{i}$ and $n_{n}=n_{\mathrm{CDP}}-n_{e}$, we get the dependence of the concentration of electrons in CDP on the temperature $T[13,14]$ :

$n_{e}=-\frac{f(T)}{2}+\left[\frac{f^{2}(T)}{4}+f(T) n_{\mathrm{CDP}}\right]^{1 / 2}$.

Here,

$f(T)=2\left(\frac{2 \pi m_{e} k T}{h^{2}}\right)^{3 / 2} \exp \left(-\frac{A_{2}}{k T}\right)$.

If the temperature of particles $T_{1} \geq T_{2}$ in relation (5), $T=T_{2}$. CDP is formed near the particle surface at the temperature of the particle $T_{1}<T_{2}$. In this case, $T=T_{1}$ in relation (5). The dependence of the concentration of electrons in CDP on the temperature of a particle $T_{1}$ is presented in Fig. 3.

The particle gets a negative charge, if the electron current from CDP to the surface of the particle is more than the electron current from the surface of the particle. The condition of the charge equilibrium of the particle with CDP in the region of the negative charge on the particle has the form

$$
\begin{aligned}
& \pi r^{2} n_{e} e \bar{v}_{e}\left[1-\frac{e l_{1}}{4 \pi k T_{2} \varepsilon_{0} r^{2}}\left(Q^{1 / 2}-\frac{r e^{1 / 2}}{2 l_{1}}\right)^{2}\right]= \\
& =4 \pi r^{2} A T_{1}^{2} \exp \left(-\frac{A_{1}-\Delta A_{1}}{k T_{1}}\right) .
\end{aligned}
$$

Here, $r$ is the radius of a spherical metal particle, $Q$ is the particle charge, $l_{1}=l_{0}\left(T_{1} / T_{0}\right)$ is the width of the kinetic zone of a particle, where $l_{0}$ is the width of the kinetic zone of a particle at $T_{0}=273 \mathrm{~K}[1,2], A$ is the Richardson-Dushman constant, $\bar{v}_{e}=\left(8 k T_{2} / \pi m_{e}\right)^{12}$ is the mean speed of electrons, $\Delta A_{1}$ is a reduction of the work function of an electron from the surface of a particle carrying a negative charge, $\Delta A_{1}$ is defined by the Schottky effect $\Delta A_{1}=Q^{1 / 2} e^{3 / 2} / 4 \pi \varepsilon_{0} r[1,2]$, and $A_{1}$ is the work function of an electron from a particle. The right-hand side of relation (6) characterizes the flux of negative charge from the particle surface. The lefthand part of relation (6) is the flux of negative charge from CDP to the surface of a particle. The expression in square brackets defines the braking of the current of electrons in the kinetic zone of a particle. There is the potential barrier inside the kinetic zone of the particle carrying a negative charge. This barrier is caused by a superposition of the electrostatic field of pushing away of a particle and the field of mirror reflections of an electron charge $[1,2]$. The potential barrier inside the kinetic zone of a particle is absent for a negative charge of a particle, the value of which satisfies to the inequality $0<Q \leq\left[e r^{2} /\left(4 l_{1}^{2}\right)\right]$. Relation (6) is simplified in this case:

$n_{e} \bar{v}_{e} e=4 A T_{1}^{2} \exp \left(-\frac{A_{1}}{k T_{1}}+\frac{Q^{1 / 2} e^{3 / 2}}{4 \pi \varepsilon_{0} r k T_{1}}\right)$.

Hence,

$Q=\left[\frac{4 \pi \varepsilon_{0} r k T}{e^{3 / 2}} \ln \frac{n_{e} \bar{v}_{e} e \exp \left(-\frac{A_{1}}{k T_{1}}\right)}{4 A T_{1}^{2}}\right]^{2}$.

If the temperature of a particle $T_{1}<T_{2}$, then $T_{1}$ instead of $T_{2}$ should be taken in (6). The mean velocity of an electron is determined by the temperature $T_{1}$ 


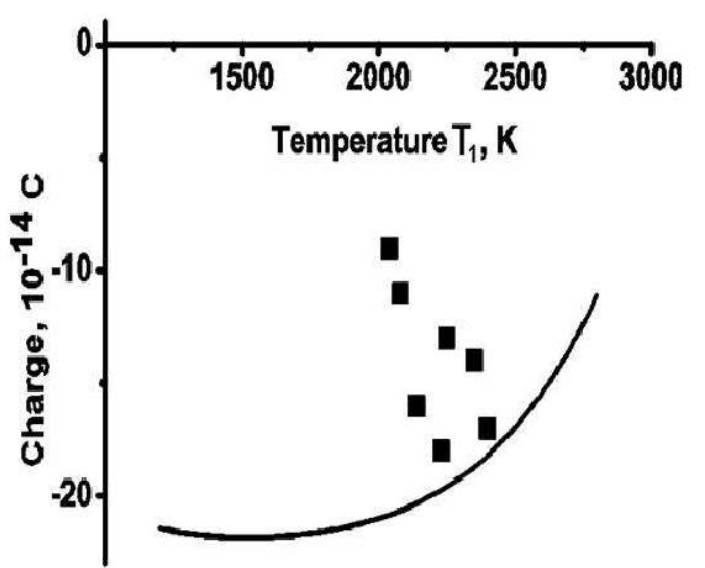

Fig. 4. A copper particle surrounded with CDP which consists of $\mathrm{Cu}_{2} \mathrm{O}$

$\bar{v}_{e}=\left(8 k T_{1} / \pi m_{e}\right)^{1 / 2}$. The numerical solution of the system of equations (1), (2), (4), (5), (6), (8) gives a possibility to find the dependence of the negative charge of a particle on its temperature $T_{1}$. The particle will get a positive charge, if the thermoemission current from its surface superpasses the flux of negative charge from CDP to the particle. The condition of charge equilibrium of the particle with CDP in the region of a positive charge has the form:

$4 \pi r^{2} A T_{1}^{2} \exp \left(-\frac{A_{1}+\frac{Q e}{4 \pi \varepsilon_{0} r}}{k T_{1}}\right)=\pi r^{2} n_{e} e \bar{v}_{e}$.

Hence,

$Q=\frac{4 \pi \varepsilon_{0} r k T_{1}}{e} \ln \left(\frac{4 A T_{1}^{2}}{\bar{v}_{e} n_{e} e}\right)-\frac{4 \pi \varepsilon_{0} r A_{1}}{e}$.

The numerical solution of the system of equations (1), (2), (4), (5), and (10) gives a possibility to find the dependence of the positive charge of a particle on its temperature $T_{1}$. Figure 4 presents the experimental (black rectangles) and calculated (solid line) dependences of the equilibrium charge located on a spherical particle of melted copper with $r=117 \mu \mathrm{m}$ on its temperature. Figure 5 presents the analogous dependences (black rectangles are experimental values of a charge and a solid line gives calculated values) for a spherical particle of tantalum with $r=185 \mu \mathrm{m}$. The width of the kinetic zone of a particle and the middle value of the particle of CDP in the presented scheme are conditional. CDP which surrounds the particle of tantalum, except $\mathrm{Ta}_{2} \mathrm{O}_{5}$, contains oxides $\mathrm{TaO}_{5}$ and $\mathrm{Ta}_{2} \mathrm{O}$. The problem contains many parameters. That's why the correlation between experimental and calculated data can be regarded as satisfactory. The results which have been obtained are very

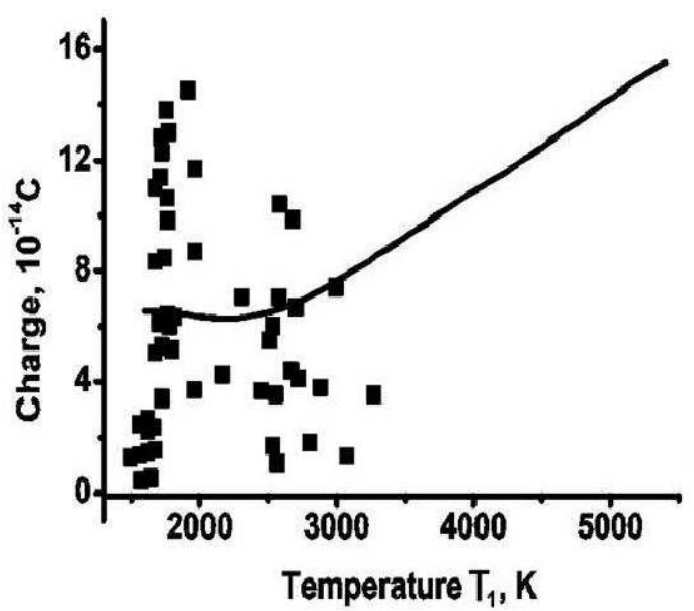

Fig. 5. A tantalum particle surrounded with CDP which consists of $\mathrm{Ta}_{2} \mathrm{O}_{5}$

important in the research of the charge and mass transfer processes in disperse systems.

1. L.A. Lyalin, K.I. Semenov, V.V. Kalinchak, A.S. Chernenko, Ukr. J. Phys. 50, 157 (2005).

2. K.I. Semenov, L.A. Lyalin, V.V. Kalinchak, N.Kh. Kopyt, A.S. Chernenko, Ukr. J. Phys. 53, 1073 (2008).

3. L.A. Lyalin, K.I. Semenov, V.V. Kalinchak, and N.Kh. Kopyt, in Abstracts of European Aerosol Conference (Budapest, Hungary, 2004).

4. L.A. Lyalin, K.I. Semenov, V.V. Kalinchak, A.I. Shvets, and N.Kh. Kopyt, Fiz. Aerodisp. Sist. 46, 150 (2009).

5. V.I. Vishnyakov and G.S. Dragan, in XXII Sci. Conference on Dispersed Systems of CIS countries (Odessa, Ukraine, 2006).

6. K.V. Kolesnikov, G.S. Dragan, and V.I. Vishnyakov, in XXIII Sci. Conference on Dispersed Systems of CIS countries (Odessa, Ukraine, 2008).

7. G.N. Churilov, A.S. Fedorov, P.V. Novikov, and Yu.S. Martines, in Int. Conference "Dusty Plasmas in Applications" (Odessa, Ukraine, August 25-28, 2004).

8. L.G. Dyachkov, A.G. Khrapak, and S.A. Khrapak, in 2nd Int. Conference on Physics of Dusty and Burning Plasmas (Odessa, Ukraine, 2007).

9. A.A. Arshinov and A.K. Musin, Dokl. AN SSSR120, 747 (1958). 
10. B.M. Smirnov, Uspekhi Fiz. Nauk 170, 495 (2000).

11. K.I. Semenov, L.A. Lyalin, V.V. Kalinchak, A.S. Chernenko, A.S. Chernenko, in Abstracts of XXII Sci. Conference on Dispersed Systems of CIS countries (Odessa, Ukraine, 2006).

12. Yu.M. Petrov, Clusters and Small Particles (Nauka, Moscow, 1987) (in Russian).

13. A.S. Chernenko, L.A. Lyalin, V.V. Kalinchak, and K.I. Semenov, in Abstracts of XXIII Sci. Conference on Dispersed Systems of CIS countries (2008).

14. L.A. Lyalin, K.I. Semenov, and N.Kh. Kopyt, in Modern Problems of Chemical and Radiation Physics (OIHF RAN, Chernogolovka, 2009), p. 49.

Received 22.11.10
ТЕМПЕРАТУРНА ЗАЛЕЖНІСТЬ РІВНОВАЖНОГО ТЕРМОЕМІСІЙНОГО ЗАРЯДУ МЕТАЛЕВОЇ ЧАСТИНКИ, ЩО ОТОЧЕНА НАНОДИСПЕРСНОЮ КОНДЕНСОВАНОЮ ФАЗОЮ

Л.А. Лялін, К.І. Семенов, А.К. Семенов, В.В. Калінчак, H.X. Konum

$\mathrm{P}$ е $з$ ю м е

У роботі представлено фотографії конденсованої дисперсної фази (КДФ), яка оточує нагріту металеву частинку, що виконані з застосуванням електронного мікроскопа. Отримано залежності концентрації частинок КДФ і концентрації електронів у КДФ від температури частинки. Отримано умову зарядової рівноваги металевої частинки, яку оточує нано-КДФ. Отримано залежність рівноважного заряду металевої частинки, яка оточена нано-КДФ, від температури частинки в позитивній i негативній областях. Отримані результати можуть бути використані у дослідженнях горіння металізованих палив і в дослідженнях пилової плазми. 